Revista PSICOLOGIA, 2020, Vol. 34 (1), 195-213. doi: 10.17575/psicologia.v34i1.1475

\title{
Avaliação da saúde dos professores portugueses: 0 Questionário de Saúde Docente
}

\author{
Liberata Borralho ${ }^{1,2}$, Saúl Neves de Jesus ${ }^{2}$, João Viseu² \& Adelinda Candeias ${ }^{3}$ \\ ${ }^{1}$ Centro de Investigação em Educação e Psicologia - Universidade de Évora \\ ${ }^{2}$ Centro de Investigação em Turismo, Sustentabilidade e Bem-estar - Universidade do Algarve \\ ${ }^{3}$ Comprehensive Health Research Centre - Universidade de Évora
}

\begin{abstract}
Resumo: Nas últimas décadas temos assistido a uma crescente deterioração da saúde docente, que afeta os professores e a escola enquanto organização. Este estudo pretendeu avaliar a saúde dos professores portugueses através do Questionário de Saúde Docente, numa amostra de 5009 professores. Os resultados das análises fatoriais suportam uma estrutura penta-fatorial (bem-estar profissional, esgotamento, distúrbios cognitivos, distúrbios musculosqueléticos, alterações da voz), com bons indicadores de qualidade do modelo com cinco fatores correlacionados (modelo 2). Os resultados indicaram que mais da metade dos professores apresenta problemas de saúde. Os do ensino público, 1.은 ciclo, género feminino, com mais de 50 anos e 21 ou mais anos de serviço, são os que apresentam menor bem-estar e maior perda de saúde. A análise de clusters forneceu uma solução de três grupos: saúde alta, média e baixa. São discutidos os resultados e suas implicações individuais e organizacionais, bem como são fornecidas diretrizes para investigações futuras.
\end{abstract}

Palavras-chave: Saúde docente; saúde ocupacional; riscos laborais; bem-estar profissional.

Health assessment of portuguese teachers: The Teacher's Health Questionnaire: In the last decades we have witnessed a deterioration of teacher's health, which affected teachers and the school as an organization. This study aimed to evaluate the health of Portuguese teachers through the "Teacher's Health Questionnaire", in a sample of 5009 teachers. The results of the factor analysis supported a fivefactor structure (professional well-being, exhaustion, cognitive disorders, musculoskeletal disorders, and voice alterations), with good fit indexes that supported the quality of the model with five-correlated factors (model 2). The results indicate that more than half of teachers have health problems. Those from public education, $1^{\text {st }}$ cycle, feminine gender, with more than 50 years and 21 or more years of service are those that present less well-being and more health loss. Cluster analysis provided a solution of three groups: high, medium, and low health. The results and their individual and organizational implications are discussed, as well as guidelines for future research.

Keywords: Teacher's health; occupational health; work risks; professional well-being.

Nas últimas décadas temos assistido a uma crescente deterioração da saúde docente que afeta os professores e a escola enquanto organização (Jesus, 2004; Klusmann, Richter, \& Lüdtke, 2016; Mack, Jonhson, Ricon, Tsatenawa, \& Howard, 2019; Ramos, 2012; Rumschlag, 2017; Scheuch, Haufe, \& Seibt, , 2015). Vários estudos (e.g., Esteve, 1994; Gil-Monte, 2005; Jesus \& Conboy, 2001; Jesus \& Resende, 2009; Ramos, 2012; Rumschlag, 2017) associam esta situação a fenómenos como o mal-estar docente, a desmotivação, a insatisfação profissional, o absentismo, assim como ao recente incremento no número de professores, do ensino básico e secundário, a pedir a antecipação da reforma e a abandonar a profissão.

As escolas, enquanto organizações, devem responder por objetivos relativos ao cumprimento de um serviço público de educação que garanta o acesso universal e maximize as possibilidades de todos os alunos atingirem elevados níveis de sucesso. Para assegurar que estes objetivos são cumpridos, é imprescindível que o professor se sinta saudável, satisfeito, competente e ativo no seu contexto laboral e que disfrute de bem-estar, energia e relações de apreço (Chambel, 2016). Neste sentido, na avaliação da saúde docente, entende-se que um professor está saudável não só quando não está doente, mas também quando apresenta um estado de funcionamento ótimo, está motivado para o seu trabalho, satisfeito, comprometido com a escola e adaptado ao contexto onde exerce a sua atividade profissional (FernándezPuig, Mayayo, Lusar, \& Tejedor, 2015a). A própria definição de saúde como um estado de bem-estar físico,

1 Morada de correspondência: Liberata Borralho, Colégio Pedro da Fonseca. PITE, Rua da Barba Rala, nº 1, 7005-345 Évora. E-mail: libjesus@uevora.pt 
mental e social, e não apenas a ausência de doença (World Health Organization [WHO], 1947), enquadrase nesta perspetiva. Assim sendo, os instrumentos de avaliação da saúde docente devem incluir, também, aspetos específicos relacionados com o bem-estar profissional e com o funcionamento ótimo dos professores (Salanova, Martínez, \& Llorens, 2014).

Uma contribuição recente nesta perspetiva foi o desenvolvimento do Cuestionário de Salud Docente (Fernández-Puig et al., 2015a). Este é um instrumento de origem espanhola, construído e validado com base numa amostra de 6208 professores de 197 centros educativos da Catalunha (Espanha) que inclui, simultaneamente, as principais manifestações de deterioração da saúde e de bem-estar nos professores, num formato breve, sendo muito útil do ponto de vista da avaliação da saúde e da investigação.

o Cuestionário de Salud Docente permite obter informações não só sobre o estado de saúde individual do docente, através da perceção que este tem sobre a sua própria saúde, mas também de um coletivo de docentes, visto que quando é aplicado a um grupo especifico de professores, em função de variáveis sociodemográficas e profissionais (e.g., género, idade, tempo de serviço, nível de ensino), permite identificar e prevenir problemas de saúde e situações de riscos profissionais específicos. Pode, ainda, dar-nos indicações para a construção de programas de intervenção diferenciados, adequados a um determinado grupo/coletivo de docentes. Possibilita, ainda, avaliar a saúde da organização escolar, tendo como referência a definição de saúde organizacional preconizada por Jaffe (1995). Segundo este autor, a saúde de uma organização deve focar-se na saúde dos seus colaboradores, de modo a garantir que estes apresentam níveis adequados de saúde física e mental, e de bem-estar, uma vez que só assim é possível alcançar uma boa performance e atingir os objetivos organizacionais. A construção deste questionário teve como referência modelos teóricos que consideram as dimensões positivas e negativas da saúde laboral: o modelo duplo de espirais positivas e negativas de saúde ocupacional (Salanova, Llorens, \& Schaufeli, 2011; Salanova et al., 2014) e o modelo de Rudow (1999).

Estes modelos incluem os aspetos explicativos de uma profissão e mostram não só as dimensões negativas, mas também as positivas, fundamentais na construção de uma profissionalidade docente saudável (Fernández-Puig, Chamarro, \& Longás, 2015b). Ambos entendem a saúde docente como um processo em espiral positiva, gerador de motivação, competência, satisfação, oposto a um processo em espiral negativa ou de deterioração da saúde, caraterizado por uma vivência reiterada de fracasso, que produz esgotamento e conduz a uma falta de motivação e de satisfação e, a longo prazo, à perda de saúde.

Os constructos considerados por Salanova et al. $(2011,2014)$ na espiral positiva (ganho de saúde) são a autoeficácia, os sentimentos positivos (entusiasmo, satisfação e dedicação) e o engagement no trabalho (vigor, dedicação e absorção). Por sua vez, o modelo de Rudow (1999) articula os processos de interação entre o individuo e o contexto laboral, considerando este que as disposições física e psicológica do indivíduo, a competência, a eficácia, a satisfação e a motivação, são constructos importantes no ganho de saúde do docente. Estes modelos, desenvolvidos no âmbito da psicologia da saúde ocupacional, integram a avaliação dos aspetos de deterioração da saúde, tais como os distúrbios, as alterações e as patologias, assim como os relacionados com o bem-estar na atividade laboral, sendo, por isso, considerados modelos de referência na construção deste questionário.

o Cuestionário de Salud Docente foi construído com base numa amostra de professores espanhóis do ensino básico e secundário, sendo este um dos motivos que justifica a não inclusão de professores do ensino superior neste estudo, uma vez que se pretendia contribuir para a validação do instrumento em professores portugueses do mesmo nível de ensino, o que também possibilitaria a realização de um futuro estudo envolvendo professores de Portugal e Espanha. Por outro lado, o facto de as carreias profissionais dos professores do ensino não superior e superior serem muito distintas, poderia enviesar os resultados deste estudo.

A pertinência deste estudo prende-se com a robustez psicométrica do instrumento nos contextos em que foi adaptado, pela escassez de instrumentos com estas características em Portugal, e pela necessidade crescente de avaliar as várias dimensões de saúde junto do corpo de docentes do ensino básico e secundário.

Destacamos, ainda, o facto de que ao ser um instrumento que abrange várias dimensões relacionadas com a saúde e bem-estar, possibilita termos uma visão biopsicossocial dos professores, em conformidade com a definição de saúde estabelecida pela OMS (1947). A aplicação e interpretação dos resultados do QSD, contribui para sensibilizar as entidades governamentais, no sentido da adoção de políticas que promovam a saúde e o bem-estar ocupacional dos professores e consequente melhoria da qualidade do ensino.

\section{Estudos sobre a saúde docente}

São vários os estudos nacionais e internacionais (e.g., Fernández-Puig et al., 2015a; Federação Nacional da Educação - FNE, 2015; Scheuch et al., 2015) que descrevem os principais problemas de saúde entre os 
professores, com destaque para os fatores psicossociais, sendo os mais comuns o stresse e o burnout, seguindo-se os distúrbios cognitivos, as alterações relacionadas com a voz e as lesões músculoesqueléticas.

Os fatores de tipo psicossocial afetam a saúde através da vivência do stresse negativo (i.e., distress) crónico, aumentando o risco de desenvolvimento de alterações emocionais e cognitivas (e.g., ao nível da concentração, da memória e do pensamento obsessivo), assim como da síndrome de burnout (European Trade Union Committee for Education - ETUCE, 2011; Gil-Monte, 2005; Maslach, Schaufeli, \& Leiter2001, Yang, You, Zhang, Lian, \& Feng, 2019). Esta síndrome caracteriza-se por uma perda de saúde que resulta de um processo de longa duração, em que o professor sente que os seus recursos para lidar com as exigências laborais estão esgotados (Santos, 2011). Este esgotamento pode ser avaliado pela perceção que o docente tem da exaustão física e emocional provocada pelo desempenho da sua atividade profissional. Dois estudos realizados no Brasil (Borba, Diehl, Santos, Monteiro, \& Marin, 2015; FerreiraEsteves, Santos, \& Rigolon, 2014) observaram valores de burnout mais elevados em docentes das escolas públicas. Os estudos realizados em Portugal (e.g., Santos, 2011), Estados Unidos da América (e.g., Rumschlag, 2017) e Alemanha (e.g., Scheuch et al., 2015) concluíram que as mulheres sofrem mais desta síndrome, sendo mais evidente nos docentes do ensino secundário (Fernández-Puig et al., 2015b; Dubey \& Kumar, 2017). Num estudo realizado com professores cipriotas, Kokkinos (2007) concluiu que a incidência de burnout aumenta com o tempo de serviço. Em Portugal, foram vários os estudos realizados nas últimas décadas (e.g., Carlotto, 2011; Gomes, Montenegro, \& Paixão, 2010; Jesus \& Conboy, 2001; Jesus, 2002; Jesus, 2007; Martins, 2008; Patrão, Rita, \& Marôco, 2012; Ramos, 2012) que confirmaram a existência de elevados níveis de stresse e burnout nos professores.

Podemos avaliar os distúrbios cognitivos nos docentes pela presença de disfunções nas capacidades cognitivas de concentração, memória e pensamento obsessivo. Esta sintomatologia está relacionada com situações de cansaço e/ou esgotamento, e é consequência da elevada concentração de glucocorticoides no hipotálamo provocada pela vivência de esgotamento emocional e de distress (Fernández-Puig et al., 2015a). É um dos efeitos que contribuem para o desenvolvimento de espirais negativas de perda de saúde, por diminuir a eficácia profissional e aumentar as possibilidades de desenvolvimento de burnout, isolamento social, distância e desmotivação (Fernández-Puig et al., $2015 b$ ). Cerca de metade dos professores brasileiros e argentinos do género feminino apresentaram uma diminuição das suas capacidades cognitivas, nomeadamente as relacionadas com a memória, os pensamentos obsessivos (Júnior \& Lipp, 2008) e as dificuldades de concentração (Asociación Docente de Enseñanza Media y Superior [ADEMYS], 2011; Júnior \& Lipp, 2008). Os professores espanhóis também manifestaram este tipo de perturbação, observando-se que esta aumentava com a idade e com o tempo de serviço, sendo mais comuns nas mulheres (Fernández-Puig et al., 2015b). Ainda neste âmbito, pode-se observar que não existiram diferenças significativas relativamente às perturbações cognitivas no que diz respeito ao nível de ensino dos docentes (Fernández-Puig et al., 2015b).

As alterações da voz podem ser avaliadas pela presença de sensações físicas de mal-estar relacionadas com a voz, em concreto a afonia, ou perda da voz, fadiga vocal e dores de garganta (Valente, Botelho, \& Silva, 2015). As evidências empíricas indicam que a docência é uma profissão de alto risco para o desenvolvimento de perturbações da voz, sendo mais comum a presença destas nas mulheres dos ensinos pré-escolar e 1. o ciclo (ADEMYS, 2011; Alva, Machado, Bhojwani, \& Sreedharan, 2017; FernándezPuig et al., 2015b; Nusseck, Spahn, Echternach, Immerz, \& Richter, 2018). Não se constataram diferenças significativas em função da idade e do tempo de serviço nos estudos realizados com professores indianos (Alva, Machado, Bhojwani, \& Sreedharan, 2017), espanhóis (Fernández-Puig et al., 2015b) e brasileiros (Valente, 2015). Em Portugal, os escassos estudos nesta área apontam para uma incidência de problemas vocais em mais de metade dos professores (Guimarães, 2004), registando-se uma maior incidência nas mulheres (FNE, 2015).

Os distúrbios musculosqueléticos relacionados com o trabalho incluem um grupo de doenças dos músculos, tendões, articulações e nervos (Erick \& Smith, 2011). Podem ser avaliados pela presença de dor nas costas, sendo mais frequentes as contraturas, as dores cervicais e dorsais, as hérnias discais e as lombalgias (Erick \& Smith, 2011). Os estudos realizados em Espanha (Fernández-Puig et al., 2015b), na Polónia (Rottermund et al., 2015), na China (Yue, Fengying, Liu, \& Li, 2012) e na Malásia (Zamri, Moy, \& Hoe, 2017) consideraram que este é um problema comum entre os professores. Mesaria e Jaiswal (2015) verificaram que os professores da Turquia, China, Austrália, Brasil, Suécia, Estados Unidos da América, Alemanha, Estónia, Japão, Malásia, Filipinas, França e Grécia apresentavam uma ocorrência elevada de problemas musculosqueléticos. 0 estudo de Yue et al. (2012) concluiu que cerca de metade dos professores chineses têm dores no pescoço/ombro e na região lombar, sendo as mulheres a sofrer mais destes problemas. Por sua vez, Fernández-Puig et al. (2015b) verificaram que são as mulheres, os 
professores entre os 45 e os 55 anos, e que lecionam no ensino pré-escolar os que mais sofrem destes distúrbios. Estes acentuam-se à medida que o tempo de serviço aumenta.

São vários os constructos associados ao bem-estar na vida profissional, tais como a satisfação, a autoeficácia, a motivação, o engagement, o flow (Fernández-Puig et al., 2015a; Jesus et al., 2011; LópezAraujo, Segovia, \& Peiró, 2007; Salanova et al., 2014; Zacharias et al., 2011), pelo que devem ser considerados na avaliação do estado ótimo de saúde ou bem-estar.

A satisfação no trabalho tem sido utilizada para perceber o nível de bem-estar no trabalho. A maioria dos teóricos define a satisfação docente como um sentimento e forma de estar positivos perante a profissão e que tem origem em fatores contextuais e/ou pessoais (Sousa, 2016). Já a autoeficácia profissional define-se como a convicção de possuir as capacidades profissionais e competências necessárias para organizar e executar o trabalho e atingir os objetivos (Fernández-Puig et al., 2015a).

Por sua vez, Lisboa (2012) define o termo de motivação como o processo de fornecer aos colaboradores a oportunidade de satisfazer as suas necessidades psicológicas, o que irá levar a um comportamento produtivo dentro da organização. O engagement pode ser considerado como um componente da motivação, uma vez que um engagement elevado aponta para uma motivação ligada à satisfação das referidas necessidades. Existem algumas semelhanças entre as definições de engagement no trabalho e de motivação profissional, uma vez que ambas se referem à presença de uma energia, em contexto laboral, que faz com que os sujeitos se envolvam nas suas tarefas com o objetivo de as superar (Viseu, 2017).

$\mathrm{Na}$ atividade docente diz-se que um professor apresenta um nível elevado de bem-estar se manifesta uma elevada satisfação profissional, elevadas expectativas de eficácia, se sente motivado para o exercício das suas funções, desejo de continuar na profissão, e apresenta baixos índices de stresse e burnout (Jesus, 2007; Jesus et al., 2011). Neste sentido, o bem-estar profissional pode ser avaliado através da satisfação, motivação, prazer, energia e sensação de felicidade no exercício da docência (López-Araujo et al., 2007), assim como pela perceção que o professor tem sobre a sua competência e capacidades profissionais para obter resultados positivos e significativos. 0 bem-estar profissional aponta para a existência de um estado afetivo positivo em relação à docência, o que facilita o desenvolvimento de espirais de ganho de saúde, sendo, por isso, um elemento relevante na prevenção da saúde ocupacional (Salanova et al., 2011).

Dybowski, Sehner e Harendza (2017) referem a relação de alguns destes constructos com o bemestar físico e psicológico e com uma boa qualidade nas relações interpessoais. Os resultados obtidos por Zacharias et al. (2011) mostraram que cerca de metade dos professores brasileiros manifestam satisfação e bem-estar no trabalho, apresentando as mulheres valores significativamente superiores. Por sua vez, os resultados obtidos por Fernández-Puig et al. (2015a) permitem afirmar que os professores espanhóis manifestam maior satisfação com a sua atividade profissional que os brasileiros, sendo também as mulheres a revelar um nível mais elevado de satisfação. Os mesmos autores obtiveram níveis mais elevados de satisfação para os professores mais jovens e com menos tempo de serviço, a lecionar no ensino pré-escolar e 1. ${ }^{-}$ciclo. De referir que a maioria dos professores espanhóis se sente eficaz e competente no exercício da sua atividade profissional, especialmente as mulheres do ensino pré-escolar, diminuindo esta perceção à medida que a idade e o tempo de serviço aumentam.

O presente estudo teve como objetivos: (a) adaptar e validar o Cuestionário de Salud Docente (Fernández-Puig et al., 2015a) para professores portugueses dos ensinos básico e secundário, por forma a colmatar a inexistência de um instrumento único e completo que permita realizar esta avaliação, tendo em conta as especificidades inerentes ao desempenho profissional do professor e às problemáticas específicas da profissão; e (b) avaliar o estado de saúde docente através da análise da distribuição das respostas em função das dimensões do questionário, dos resultados da comparação entre grupos em função das variáveis género, idade, tipo de instituição, tempo de serviço e nível de ensino e dos resultados da análise de clusters.

\section{MÉTODO}

\section{Participantes}

A amostra deste estudo era composta por 5009 professores (3889 mulheres, $77.6 \%$ e 1120 homens, 22.4\%) dos ensinos básico e secundário a lecionar em escolas de Portugal. A amostra integrou 4603 (91.9\%) professores do ensino público e 406 (8.1\%) do ensino privado. A média de idades foi de 48.4 anos $(D P=7.8)$, sendo que a idade mínima foi 21 anos e a máxima 70 anos. No que se refere ao tempo de serviço, 3078 (61.4\%) tinha mais de 20 anos de ensino, 29.2\% tinha entre 11 e 20 anos, 6.6\% entre 6 e 10 anos e 2.8\% tinha até 5 anos de docência. Participaram 305 professores do ensino pré-escolar (6.1\%), 
754 (15.1\%) do 1.. ensino especial e 56 (1.1\%) do ensino profissional e artístico (técnicos especializados).

\section{Instrumentos}

o Cuestionário de Salud Docente de Férnandez-Puig et al. (2015a) é um instrumento de origem espanhola que tem como objetivo conhecer a perceção dos docentes sobre o seu estado de saúde. Reúne 23 itens baseados na perceção do sujeito sobre a vivência positiva da docência e sobre a presença de sintomas físicos e psicológicos relacionados com os riscos laborais desta profissão: satisfação (5 itens), autoeficácia (5 itens), esgotamento (3 itens), distúrbios da voz (3 itens), distúrbios musculosqueléticos (3 itens) e distúrbios cognitivos (4 itens). Este questionário utiliza uma escala de Likert de 5 pontos: (1 - Discordo totalmente; 5 - Concordo totalmente). Os resultados da análise de fiabilidade mostraram-nos que a consistência interna dos fatores apresentava valores de Alpha de Cronbach entre .71 e .87, pelo que se considerou que a consistência interna do questionário é satisfatória (Fernández-Puig et al., 2015a).

Foi igualmente criado um questionário sociodemográfico e profissional que continha dados pessoais e informações relativas ao género, idade dos participantes, anos de serviço, nível de ensino e tipo de instituição onde exerciam funções.

\section{Procedimentos}

Este estudo transversal seguiu uma metodologia de cariz quantitativo (Montero \& León, 2007). Depois de concedida autorização pelos autores do Cuestionário de Salud Docente (Fernández-Puig et al., 2015), procedemos à sua adaptação para a cultura portuguesa, de acordo com os procedimentos sugeridos por Gjersing (2010):

a) Adaptação à língua portuguesa utilizando método de tradução por duas pessoas bilingues (português e espanhol).

b) Um profissional da área da Psicologia da Saúde avaliou a equivalência de conteúdo entre a versão portuguesa e a original (retroversão independente).

c) A versão preliminar foi aplicada online a uma amostra de seis professores para avaliar a sua compreensão e viabilidade (estudo piloto). Após o preenchimento do questionário, os indivíduos foram questionados sobre: compreensão e pertinência das questões, adequação da escala de resposta, facilidade e tempo de preenchimento. Todos os respondentes referiram boa compreensão e aceitação das questões apresentadas.

d) Após a aprovação por parte da Direção Geral da Educação (registo 057300002), o Questionário de Saúde Docente (versão portuguesa) foi submetido, em janeiro de 2017, a uma aplicação online mais alargada através da plataforma Limesurvey com vista à análise da sua aplicabilidade aos professores portugueses, cujos resultados serviram de objeto ao presente estudo.

Foi enviado um email, com o texto de apresentação e link de preenchimento, a todas escolas/agrupamentos de Portugal a solicitar a sua divulgação por todos os docentes dos ensinos básico e secundário. Este estudo seguiu as recomendações para melhorar a qualidade das investigações via Web, baseado na lista de verificação para relatar resultados de E-Surveys via internet (CHERRIES) (Eysenbach, 2014). O texto de apresentação cumpria os compromissos éticos definidos para investigação em educação, nomeadamente aqueles que se referem ao consentimento informado, livre e esclarecido, de todos os que nele participam. Foram fornecidas informações sobre a natureza e objetivos do estudo, assim como os que se referem à confidencialidade e anonimato dos dados recolhidos. A participação era voluntária, sendo que ao submeter o questionário o(a) professor(a) estava a concordar com as condições de colaboração no estudo.

Foram obtidos 5046 questionários, dos quais 37 foram eliminados por os dados se encontrarem ilegíveis.

\section{Análise dos Dados}

Com o objetivo de verificar as propriedades psicométricas da versão portuguesa, designada de Questionário de Saúde Docente (QSD), realizaram-se as seguintes análises: (a) sensibilidade dos itens, a partir da média, desvio-padrão, mediana, moda, assimetria e curtose e correlação item-total corrigida, considerando os critérios estabelecidos por Almeida e Freire (2017); (b) análise fatorial exploratória (AFE), realizada sobre a primeira metade aleatória da amostra $(n=2506)$, através do método de extração de fatorização pelo eixo principal, com rotação oblíqua Direct-Oblimin $(\Delta=0)$, para avaliar a estrutura fatorial do instrumento em causa. A utilização deste tipo de rotação, além de respeitar os pressupostos do estudo original, também se deve ao facto de os fatores considerados poderem estar correlacionados (Marôco, 2014). Foi utilizado o critério de Kaiser-Meyer-Olkin e o teste de Esfericidade de Bartlett para verificar a adequabilidade da amostra para a realização da AFE (Marôco, 2014). Para determinar o 
número de fatores, utilizou-se o critério de Kaiser, selecionando-se os fatores com um eigenvalue superior a 1. Foram apenas considerados os itens com carga fatorial superior a .40 (Marôco, 2014). A confiabilidade da estrutura fatorial foi testada através do coeficiente Alpha de Cronbach; (c) análise fatorial confirmatória (AFC), para testar o ajustamento do modelo de referência e o funcionamento dos seus fatores, efetuada sobre a segunda metade aleatória da amostra $(n=2503)$ aplicando o método de máxima verosimilhança, visto que a análise preliminar revelou que nenhuma variável apresentava valores de assimetria $(s k)$ e curtose $(k u)$, indicadores de violações severas à distribuição normal $(|S k|<3$ e $|\mathrm{Ku}|<10$; Marôco, 2014). A existência de outliers foi avaliada pela distância quadrada de Mahalanobis $\left(D^{2}\right)$. Os outliers encontrados não foram excluídos por estarem abaixo do limiar recomendado (5\%) para que este procedimento se efetue (Hair, Black, Babin, Anderson, \& Tatham, 2009), e por se verificar que a sua presença não influenciou os resultados das análises realizadas. A qualidade de ajustamento geral do modelo foi realizada através dos seguintes índices: (a) Qui-quadrado $\left(\chi^{2}\right)$ e os graus de liberdade (df); (b) os índices de ajuste comparativo, CFI (Comparative Fit Index) e IFI (Incremental Fit Index). Valores acima de .95 indicam um ajuste ótimo e os superiores a .90 indicam um ajuste adequado (Marôco, 2014); (c) os índices de ajuste geral, GFI (Goodness Fit Index) e AGFI (Adjusted Goodness Fit Index).Valores iguais ou superiores a 90 indicam um bom ajustamento do modelo; (d) o Root Mean Square Error of Approximation (RMSEA) que indica a qualidade de ajustamento a partir de valores iguais ou inferiores a .06 (Marôco, 2014); e (e) o SRMR (Standardized Root Mean Square Residual), valores menores ou iguais a .08 são indicativos de um bom ajuste (Hair et al., 2009; Kline, 2011). Para comparar os diferentes modelos, utilizou-se o AIC (Akaike Information Criterion) (Marôco, 2014). A fiabilidade compósita (FC) foi avaliada como descrito por Marôco (2014). De uma forma geral, considera-se que FC $\geq 70$ é um indicador de uma fiabilidade de constructo apropriada. A validade de constructo foi determinada através de três componentes: a validade fatorial, a validade convergente e a validade discriminante, tal como sugere Marôco (2014). A validade fatorial foi avaliada pelas cargas fatoriais padronizadas $(\lambda)$ e pela fiabilidade individual dos itens $\left(\lambda^{2}\right)$. É usual assumir-se que $\lambda \geq .50$, o fator apresenta validade fatorial, e que $\lambda^{2} \geq .25$ é um indicador de fiabilidade individual apropriada. A validade convergente dos fatores foi avaliada através da variância extraída média (VEM). Valores de VEM $\geq .50$ são indicadores de uma validade convergente adequada (Hair et al., 2009). A validade discriminante dos fatores foi avaliada pela comparação das VEM com os quadrados da correlação entre os fatores $\left(r^{2}\right)$. A VEM dos fatores deve ser superior ou igual ao quadrado da correlação entre esses fatores para que a validade discriminante fique demonstrada (Marôco, 2014). Para realizar a validade cruzada, procedeu-se à divisão aleatória da amostra em dois grupos distintos. Desta forma, a AFE foi efetuada sobre a amostra $1(n=2506)$ e a AFC sobre a amostra $2(n=2503)$ (Marôco, 2014). A análise descritiva dos resultados foi realizada sobre a amostra total.

Para analisar o estado de saúde dos professores, realizou-se um estudo da distribuição das respostas em cada dimensão e uma análise da variância (ANOVA), seguida do teste post-hoc de Bonferroni ( $p=.05)$, em função do género, idade, tempo de serviço, nível de ensino, tipo de instituição, uma vez que se verificaram os pressupostos de normalidade (assimetria e curtose) e de homogeneidade (teste de Levence) das variâncias (Marôco,2018).

Com o objetivo de avaliar a saúde dos professores inquiridos, procedeu-se a uma análise de clusters, para determinar a existência de grupos homogéneos a partir de pontos de corte, tendo como referência o índice global de saúde. 0 cálculo deste índice obtém-se a partir da soma direta da escala/fator bem-estar profissional e da soma inversa das escalas distúrbios musculosqueléticos, esgotamento, alterações da voz e distúrbios cognitivos, de forma que uma pontuação alta indica um bom nível de saúde e uma pontuação baixa um nível baixo de saúde do docente. Por sua vez, a pontuação de cada escala/fator obtém-se pela soma direta dos itens correspondentes.

Inicialmente, foram utilizados métodos hierárquicos Single e Complete Linkage, aplicando como medida de dissemelhança a Squared Euclidean Distance, como técnica exploratória para determinar o número de clusters a usar, a posteriori, no método não hierárquico (K-means). 0 intuito foi refinar e interpretar a solução final de clusters (Marôco, 2018). A decisão sobre o número de clusters a reter teve como critérios a análise dos dendogramas produzidos pelo software, o número de clusters adotado no estudo realizado com a escala original (Fernández-Puig et al., 2015b) e o objetivo deste estudo. A categorização de cada cluster foi realizada tendo como referência as respetivas análises descritivas.

Para perceber qual a associação entre os clusters encontrados, que avaliam o estado de saúde dos professores, e as variáveis sociodemográficas (género, idade, tipo de instituição, tempo de serviço e nível de ensino) foram utilizadas as análises de Qui-quadrado ( $p \leq .05)$.

As análises estatísticas foram realizadas com recurso ao programa IBM SPSS (Statistical Package for Social Sciences), versão 24 e ao software AMOS (Analysis of Moment Structures), versão 24. 


\section{RESULTADOS}

\section{Adaptação e validação do QSD}

A análise da sensibilidade dos itens revelou que os dados eram executáveis à luz da normalidade (Almeida \& Freire, 2017). Com base na correlação item-total corrigida recodificaram-se todos os itens do fator "bem-estar profissional" (itens $4,6,10,11,13,15,18,19$ e 22), visto que o sentido conceptual se encontrava invertido. A inversão dos valores da escala de Likert de 5 pontos (1=5; 2=4; 4=2 e 5=1) promoveu alterações significativas na correlação item-total e na consistência interna (Alpha Cronbach) dos itens, de tal forma que o Alpha de Cronbach total passou de .681 para .918. Os valores finais após a inversão dos itens encontram-se na Tabela 1.

Tabela 1. Média, desvio-padrão, correlação item-total e Alpha Cronbach do QSD (N=5009)

\begin{tabular}{|c|c|c|c|c|}
\hline Item & $\mathbf{M}$ & DP & $\begin{array}{c}\text { Correlação } \\
\text { Item-Total } \\
\text { corrigida }\end{array}$ & $\begin{array}{c}\text { Alpha de } \\
\text { Cronbach } \\
\text { (se item } \\
\text { eliminado) }\end{array}$ \\
\hline 1. Sinto-me capaz de tomar decisões & 1.50 & .696 & .401 & .917 \\
\hline 2. Tenho dor na zona da nuca & 2.73 & 1.137 & .530 & .915 \\
\hline $\begin{array}{l}\text { 3. Tenho a impressão que fico obcecado(a) com um assunto que noutro momento } \\
\text { poderia resolver sem problema }\end{array}$ & 2.75 & .926 & .599 & .914 \\
\hline 4. Sinto-me satisfeito(a) com a minha forma de fazer as coisas & 2.15 & .791 & .573 & .915 \\
\hline 5. As minhas costas ressentem-se devido à atividade que faço & 3.46 & 1.126 & .512 & .916 \\
\hline 6. Se pudesse, voltaria a escolher ser professor(a) & 2.50 & 1.413 & .482 & .917 \\
\hline 7. Depois de um dia de trabalho sinto-me sem forças & 3.48 & 1.019 & .666 & .912 \\
\hline 8. Noto que estou afónico(a) ou disfónico(a) & 2.68 & 1.044 & .520 & .915 \\
\hline 9. Em alguns momentos, tenho falta de concentração para realizar tarefas & 2.99 & .875 & .670 & .913 \\
\hline 10. Desfruto das minhas tarefas quotidianas & 2.71 & .961 & .630 & .913 \\
\hline 11. Sou muito feliz no meu trabalho & 2.58 & .965 & .654 & .913 \\
\hline 12. Sinto-me fisicamente cansado(a) no final do meu dia de trabalho & 3.68 & 1.001 & .661 & .913 \\
\hline 13. Quando termino um trabalho, fico contente com os resultados & 2.27 & .782 & .489 & .916 \\
\hline 14. Sinto dor no pescoço depois de um dia de trabalho & 2.32 & 1.195 & .524 & .915 \\
\hline 15. Divirto-me no trabalho & 2.68 & .943 & .609 & .914 \\
\hline 16. A minha voz cansa-se facilmente & 3.00 & 1.103 & .539 & .915 \\
\hline 17. No trabalho, fico muito cansado(a) & 3.16 & 1.021 & .711 & .912 \\
\hline 18. Quando acordo, tenho vontade de ir trabalhar & 2.69 & 1.088 & .616 & .913 \\
\hline 19. Estou satisfeito(a) com a minha participação na escola & 2.31 & .913 & .583 & .914 \\
\hline 20. Há alturas/momentos em que tenho mais distrações do que o habitual & 2.89 & .785 & .280 & .919 \\
\hline 21. Sofro de lombalgia & 2.57 & 1.330 & .483 & .917 \\
\hline 22. Tenho a capacidade de ser criativo(a) e ágil na minha atividade docente & 2.35 & .840 & .478 & .916 \\
\hline 23. Ultimamente tenho falta de memória & 3.05 & 1.065 & .556 & .915 \\
\hline Total & 62.53 & 13.952 & - & .918 \\
\hline
\end{tabular}

0 valor de critério de Kaiser-Meyer-Olkin (KMO=.94) e do teste de Esfericidade de Bartlett $\left(\chi^{2}(253)\right.$, $n=2506)=29147.256 p<.0001$ ) confirmaram a adequabilidade da amostra para a realização da AFE (Marôco, 2014). A AFE revelou a existência de quatro fatores que explicavam $59.9 \%$ da variância total do constructo de saúde docente. 0 primeiro fator era composto por 9 itens $(4,6,10,11,13,15,18,19$ e 22), agregando os fatores relacionados com a perceção de satisfação e autoeficácia no desempenho da profissão do instrumento original, constructos estes associados ao bem-estar na atividade docente, motivo pelo qual o designamos de "bem-estar profissional". Este fator é o que apresentou maior percentagem de variância (37.60\%), com cargas fatoriais entre .62 e .83. 0 segundo fator indicou-nos quatro itens $(2,5,14$ e 21$)$ com cargas fatoriais que oscilaram entre .73 e .76 e que explicaram $12.53 \%$ da variância total. Este fator faz referência ao mal-estar musculosquelético, pelo que o designamos de "distúrbios musculosqueléticos". No terceiro fator foram encontrados cinco itens com cargas fatoriais superiores a $.40(7,8,12,16$, e 17), todos relacionados com a sensação de esgotamento, incluindo as 
alterações da voz, a que atribuímos a designação de "esgotamento". Este terceiro fator explicou 5.01\% da variância total e apresentou cargas fatoriais que oscilaram entre os .57 e .77. 0 quarto fator reuniu cinco itens $(1,3,9,20$ e 23) com cargas fatoriais que variaram entre .46 e .71 e que explicaram $4.79 \%$ da variância. Este último fator relacionou-se com dificuldades de carácter cognitivo, pelo que designamos de "distúrbios cognitivos". A confiabilidade da estrutura fatorial foi considerada elevada, com um coeficiente de $\alpha=.92$ (Marôco, 2014).

A AFC foi realizada com o objetivo de validar o modelo de referência M1 (4 fatores correlacionados). Os resultados demonstraram que este modelo apresenta um mau ajustamento, $\chi^{2}(224)=3292.759 \quad(p<.001), \mathrm{CFI}=.892, \mathrm{IFI}=.892, \mathrm{GFI}=.893, \mathrm{AGFI}=.868, \mathrm{RMSEA}=.074, \mathrm{SRMR}=.058$, $\mathrm{AIC}=3397.759$. Este modelo foi comparado com quatro modelos alternativos, extraídos com base na teoria e nos resultados obtidos nas várias AFE realizadas, nas duas metades aleatórias da amostra $(n=$ 2506 e $n=2503$ ), em função das variáveis género, tipo de instituição e nível de ensino e que tiveram, essencialmente, um carácter exploratório. A análise dos quatro modelos alternativos revelou que o modelo M2, com cinco fatores correlacionados (bem-estar profissional, alterações da voz, distúrbios musculosqueléticos, esgotamento e distúrbios cognitivos), apresentou um ajustamento aceitável e que os outros três (M3, M4 e M5) apresentaram um ajustamento pobre. Por sua vez, o M2 é o modelo que apresenta melhores índices de ajustamento: $\chi^{2}(220)=2249.495(p<.001), \mathrm{CFI}=.928, \mathrm{IFI}=.928, \mathrm{GFI}=.919$, $\mathrm{AGFI}=.898$, $\mathrm{RMSEA}=.061$, $\mathrm{SRMR}=.054$, $\mathrm{AIC}=2361.495$. 0 modelo $\mathrm{M} 3$ com dois macrofatores correlacionados (bem-estar profissional e distúrbios) apresentou piores índices de ajustamento que o modelo de referência (M1) e que os modelos M2 e M5 (6 fatores correlacionados: autoeficácia, satisfação, esgotamento, alterações da voz, distúrbios musculosqueléticos e distúrbios cognitivos), e melhor ajustamento que M4. 0 modelo hierárquico M4 (com 2 fatores de segunda-ordem correlacionados, bemestar e distúrbios) foi o que apresentou piores índices de ajustamento. Por último, o modelo M5 (6 fatores correlacionados) apresentou piores índices de ajustamento que M1 e M2 e melhores que M3 e M4.

De modo a melhorar o ajustamento dos modelos, foram feitas modificações a partir dos índices de modificação (superiores a 11; $p<.001$ ) produzidos pelo AMOS e com base em considerações teóricas. Outras considerações sobre as propriedades psicométricas dos modelos, nomeadamente a sensibilidade psicométrica dos itens e a consistência interna dos fatores foram ponderadas nas decisões relativas à modificação dos modelos (Marôco, 2014). Os resultados das alterações realizadas na reespecificação dos modelos melhoraram significativamente a qualidade do ajustamento. Estes valores são apresentados na Tabela 2.

Tabela 2. Índices de Ajustamento para as Cinco Estruturas Fatoriais Reespecificadas (n=2503)

\begin{tabular}{cccccccccc}
\hline $\begin{array}{c}\text { Modelo } \\
\text { modificado }\end{array}$ & $\chi \mathbf{2}$ & $\mathbf{d f}$ & CFI & IFI & GFI & AGFI & RMSEA & SRMR & AIC \\
\hline M1 & 1500.772 & 178 & .951 & .951 & .942 & .924 & .056 & .0428 & 1606.772 \\
M2 & $\mathbf{1 4 3 8 . 2 4 1}$ & $\mathbf{1 7 7}$ & $\mathbf{. 9 5 3}$ & $\mathbf{. 9 5 4}$ & $\mathbf{. 9 4 4}$ &. $\mathbf{9 2 7}$ & $\mathbf{. 0 5 3}$ & $\mathbf{. 0 4 1 9}$ & $\mathbf{1 5 4 6 . 2 4 1}$ \\
M3 & 3101.464 & 181 & .892 & .892 & .892 & .862 & .080 & .0600 & 3201.464 \\
M4 & 3008.436 & 160 & .886 & .886 & .864 & .821 & .084 & .0903 & 3108.436 \\
M5 & 2860.399 & 172 & .899 & .899 & .892 & .855 & .079 & .0735 & 2978.399 \\
\hline
\end{tabular}

Nota. M1_modificado - modelo com 4 fatores correlacionados; M2_modificado - modelo com 5 fatores correlacionados; M3_modificado - modelo com 2 macrofatores correlacionados; M4_modificado - modelo hierárquico com 2 fatores de segunda ordem correlacionados; M5_modificado - modelo com 6 fatores correlacionados; ${ }^{*} p<.001 . \chi^{2}$ - Qui-quadrado; $\mathrm{df}$ - Graus de liberdade; CFI - Comparative Fit Index; IFI - Incremental Fit Index; GFI - Goodness Fit Index; AGFI - Adjusted Goodness Fit Index; RMSEA - Root Mean Square Error of Aproximation; SRMR - Standardized Root Mean Square Residual; AIC - Akaike Information Criterion. A negrito, apresentam-se os resultados do modelo com melhor ajustamento.

De acordo com os resultados obtidos nos índices de ajustamento e tendo em conta a base teórica já apresentada, consideramos que a qualidade do ajustamento do modelo M2_modificado é boa (Marôco, 2014; Kline, 2005) e que, para além de ser o que apresenta os melhores índices de ajustamento quando comparado com os outros quatro, é aquele que melhor se adequa para avaliar a saúde dos docentes da nossa amostra, pelo que se procedeu à avaliação da sua fiabilidade e validade. Este modelo encontra-se representado na Figura 1. Como se pode constatar, 21 itens apresentam cargas fatoriais padronizadas $\geq .50$, o que revela que os fatores apresentam validade fatorial. Foram removidos os itens 1 e 20 por apresentarem fracas cargas fatoriais. A fiabilidade individual dos itens oscilou entre .36 e . 73 . 


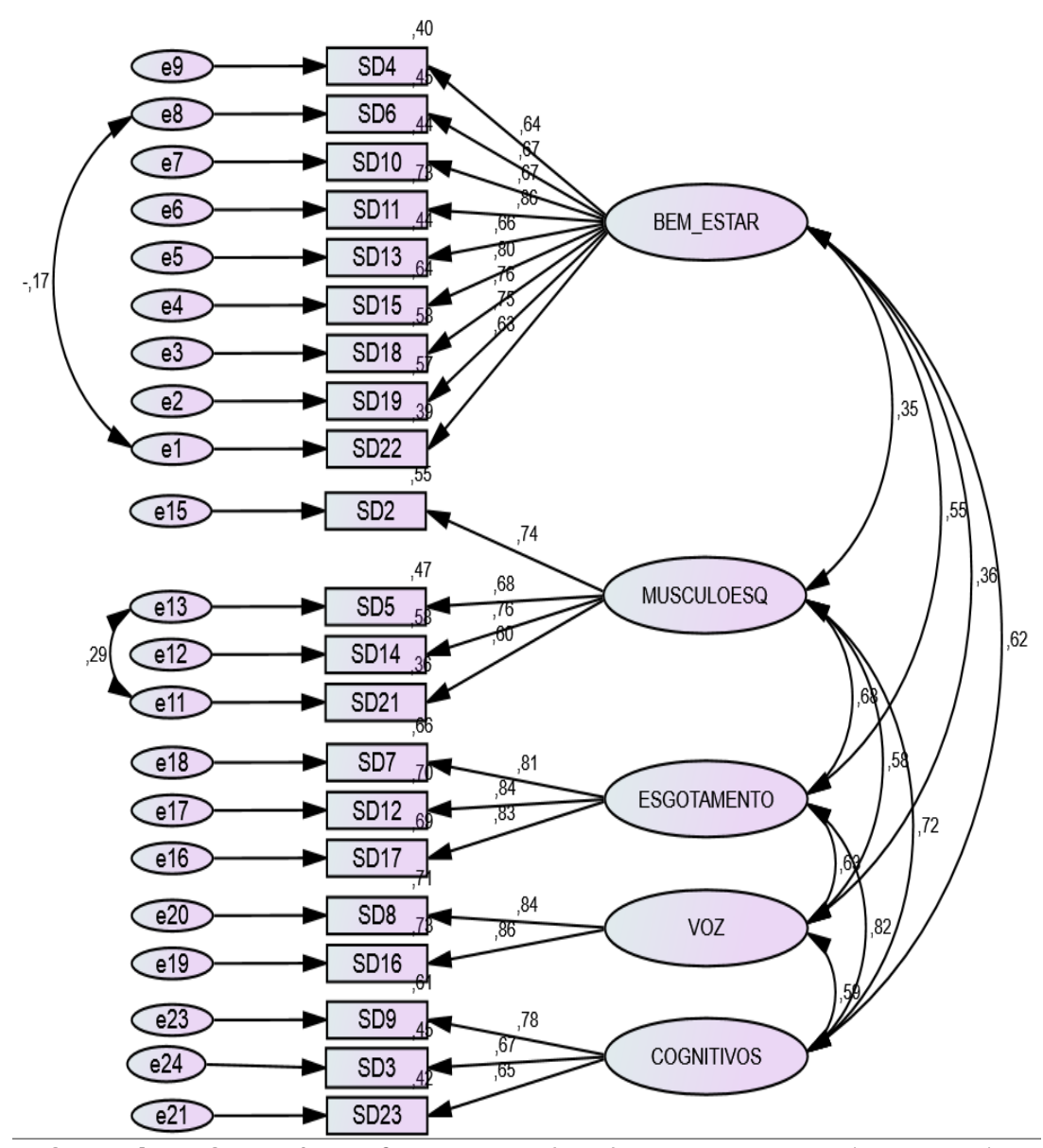

Figura 1. Análise fatorial confirmatória: $\chi^{2}=1438.241(177), p<.001 ; \mathrm{CFI}=.953 ; \mathrm{IFI}=.954 ; \mathrm{GFI}=.944$; AGFI=.927; RMSEA=.053; SRMR=.0419; $\mathrm{AIC}=1546.241$

A fiabilidade compósita revelou-se elevada, com valores entre .80 e .97. Podemos considerar que a variância extraída média (VEM), um indicador da validade convergente dos fatores, é adequada visto que apresentou valores entre .51 e .91. Todos os fatores têm validade discriminante, uma vez que o quadrado da correlação entre fatores foi superior aos valores da VEM de cada um dos fatores (valores de $r^{2}$ entre fatores oscilaram entre .14 e .49) (Tabela 3).

Tabela 3. Fiabilidade Compósita e Variância Extraída Média do Modelo Adotado (M2_modificado)

\begin{tabular}{llc}
\hline Fator & FC & VEM \\
\hline Bem-estar profissional & .91 & .52 \\
Distúrbios musculosqueléticos & .80 & .51 \\
Esgotamento & .88 & .70 \\
Alterações da voz & .84 & .72 \\
Distúrbios cognitivos & .97 & .51 \\
\hline
\end{tabular}

Nota. FC = fiabilidade compósita; VEM = variância extraída média.

\section{Caracterização da saúde dos docentes}

Na Tabela 4 apresentamos a distribuição das respostas em cada dimensão. Na dimensão "bem-estar profissional" verificamos que $14.1 \%$ dos professores manifestam frequentemente ou quase sempre bemestar no desempenho da sua atividade profissional. 
Tabela 4. Distribuição das Respostas em Relação às Dimensões (\%)

\begin{tabular}{lccccc}
\hline Dimensão & Nunca & Raramente & Algumas vezes & Frequentemente & Quase sempre \\
\hline 1.Bem-estar & 17 & 36.2 & 32.7 & 10.7 & 3.4 \\
2.Musculosq. & 20.8 & 22.4 & 25.8 & 20.8 & 10.2 \\
3.Voz & 11.2 & 27.8 & 33.8 & 20.3 & 6.9 \\
4.Esgotamento & 3.1 & 14.6 & 35 & 30 & 17.3 \\
5.Cognitivos & 6.6 & 25.6 & 40.8 & 21.9 & 5.1 \\
\hline
\end{tabular}

Nota. 1. Bem-estar profissional; 2. Distúrbios musculosqueléticos; 3. Alterações da voz; 4. Esgotamento; 5. Distúrbios cognitivos. $N=5009$

Cerca de $47 \%$ dos professores inquiridos ficam frequentemente ou quase sempre esgotados no final de um dia de trabalho, 35\% destes algumas vezes; $67.8 \%$ dos professores apresentam problemas cognitivos, $27 \%$ frequentemente ou quase sempre e $40.8 \%$ algumas vezes; $31 \%$ dos professores sentem frequentemente ou quase sempre e $25.9 \%$ algumas vezes dores nas costas e pescoço; $27.2 \%$ dos professores portugueses manifestam frequentemente ou quase sempre e $33.8 \%$ algumas vezes afonia/disfonia e cansaço vocal no final do dia de trabalho.

Atendendo a que não foram verificadas violações à normalidade $(|S k|<3$ e $|K u|<10$; Marôco, 2014), nem à homogeneidade da variância (teste de Levene com valores de $p>.05$ ) foram realizadas as análises de comparação de médias entre as variáveis apresentados nas Tabelas 5 a 8 . Os resultados devem ser lidos da seguinte forma: quanto maior o valor da média pior o estado de saúde nas várias dimensões.

Os resultados da comparação entre grupos em função do tipo de instituição (Tabela 5) são significativos para todas as dimensões, verificando-se uma diferença maior no "bem-estar profissional" $(F=45.91, p=.000)$ entre os professores do ensino público e os do privado.

Tabela 5. Resultados da Comparação de Médias em Função do Tipo de Instituição

\begin{tabular}{lccccc}
\hline Dimensão & $\begin{array}{c}\text { Público } \\
\boldsymbol{n}=\mathbf{4 6 0 3}\end{array}$ & $\begin{array}{c}\text { Privado } \\
\boldsymbol{n = 4 0 6}\end{array}$ & $\begin{array}{c}\text { Total } \\
\boldsymbol{n = 5 0 0 9}\end{array}$ & F & $\boldsymbol{p}$ \\
\hline 1.Bem-estar & 22.44 & 20.16 & 22.25 & 45.91 & $.000^{*}$ \\
2.Musculosq. & 11.15 & 10.32 & 11.08 & 17.83 & $.000^{*}$ \\
3.Voz & 5.72 & 5.16 & 5.68 & 29.80 & $.000^{*}$ \\
4.Esgotamento & 10.39 & 9.60 & 10.32 & 31.37 & $.000^{*}$ \\
5.Cognitivos & 8.84 & 8.27 & 8.80 & 22.55 & $.000^{*}$ \\
\hline
\end{tabular}

Nota. 1. Bem-estar profissional; 2. Distúrbios musculosqueléticos; 3. Alterações da voz; 4. Esgotamento; 5. Distúrbios cognitivos. ${ }^{*} p<.05 ; N=5009$.

Os resultados em função do género (Tabela 6) revelam que existem diferenças significativas em todas as dimensões ( $p=.000)$, exceto no "bem-estar profissional" ( $p=.302)$. As diferenças mais elevadas registam-se nas dimensões "distúrbios musculosqueléticos" ( $F=242.85, p=.000)$ e "esgotamento" $(F=236.85, p=.000)$, sendo as mulheres, comparativamente aos homens, as que apresentam piores médias em todas as dimensões.

Tabela 6. Resultados da Comparação de Médias em Função do Género

\begin{tabular}{lccccc}
\hline Dimensão & $\begin{array}{c}\text { Masculino } \\
\boldsymbol{n}=\mathbf{1 1 2 0}\end{array}$ & $\begin{array}{c}\text { Feminino } \\
\boldsymbol{n}=\mathbf{3 8 8 9}\end{array}$ & $\begin{array}{c}\text { Total } \\
\boldsymbol{n}=\mathbf{5 0 0 9}\end{array}$ & $\mathbf{F}$ & $\boldsymbol{p}$ \\
\hline 1.Bem-estar & 22.08 & 22.30 & 22.25 & 1.06 & .302 \\
2.Musculosq. & 9.55 & 11.52 & 11.08 & 242.85 & $.000^{*}$ \\
3.Voz & 5.10 & 5.84 & 5.68 & 123.83 & $.000^{*}$ \\
4.Esgotamento & 9.25 & 10.63 & 10.32 & 236.85 & $.000^{*}$ \\
5.Cognitivos & 8.02 & 9.02 & 8.80 & 164.85 & $.000^{*}$ \\
\hline
\end{tabular}

Nota. 1. Bem-estar profissional; 2. Distúrbios musculosqueléticos; 3. Alterações da voz; 4. Esgotamento; 5. Distúrbios cognitivos. ${ }^{*} p<.05 ; N=5009$. 
A comparação de médias em função da idade (Tabela 7) mostra diferenças significativas em todas as dimensões. A maior diferença encontra-se na dimensão "distúrbios cognitivos" $(F=11.60, p=.000)$. Os professores com idades compreendidas entre os 56 e 70 anos apresentam piores resultados na dimensão "esgotamento". Por sua vez, aqueles que estão entre os 50 e os 55 anos são os que apresentam piores médias nas dimensões "distúrbios musculosqueléticos", "distúrbios cognitivos" e "alterações da voz". Os professores mais jovens (21-42 anos) são os que apresentam melhores resultados nas dimensões de perda de saúde e maior bem-estar.

De acordo com o teste post-hoc Bonferroni, as diferenças estatisticamente significativas para a dimensão "bem-estar profissional" ocorrem entre os 21-42 anos e os 43-49 anos (I.C. a 95\% ]-1.4194;.0685[; $p=.022$ ). Já na dimensão "distúrbios musculosqueléticos", essas diferenças ocorrem entre os mais jovens e os grupos dos 43-49 anos (I.C. a 95\% ]-.9871;-.1995[; $p=.000$ ) e 50-55 anos (I.C. a 95\% ]-1.1111;.3229 [; $p=.000$ ). Nas alterações de voz as diferenças significativas manifestam-se entre o grupo dos mais jovens e os de 50-55 anos (I.C. a 95\%]-.5045;-.0930[; $p=.001$ ), assim como entre estes últimos e os de 4349 anos (I.C. a 95\% ]-.4747;-.0709[; $p=.002$ ). No que se refere às dimensões "esgotamento" e "distúrbios cognitivos" verificamos que existem diferenças estatisticamente significativas (I.C. a 95\%; $p=.000$ ) entre os mais jovens e todos os outros grupos etários.

Tabela 7. Resultados da Comparação de Médias em Função da Idade (anos)

\begin{tabular}{|c|c|c|c|c|c|c|c|}
\hline Dimensão & $\begin{array}{c}21-42 \\
n=1257\end{array}$ & $\begin{array}{c}43-49 \\
n=1351\end{array}$ & $\begin{array}{c}50-55 \\
n=1352\end{array}$ & $\begin{array}{c}56-70 \\
n=1049\end{array}$ & $\begin{array}{c}\text { Total } \\
n=5009\end{array}$ & $\mathbf{F}$ & $p$ \\
\hline 1.Bem-estar & $21.77^{\mathrm{a}}$ & $22.51^{\mathrm{a}}$ & 22.40 & 22.31 & 22.25 & 3.26 & $.021^{*}$ \\
\hline 2.Musculosq. & $10.65^{\mathrm{a}}$ & $11.24^{\mathrm{a}}$ & $11.36^{\mathrm{a}}$ & 11.04 & 11.08 & 8.76 & $.000^{*}$ \\
\hline $3 . \mathrm{Voz}$ & $5.56^{\mathrm{a}}$ & $5.58^{b}$ & $5.85^{\mathrm{a}, \mathrm{b}}$ & 5.73 & 5.68 & 6.39 & $.000^{*}$ \\
\hline 4.Esgotamento & $10.02^{\mathrm{a}}$ & $10.34^{\mathrm{a}}$ & $10.46^{\mathrm{a}}$ & $10.49^{a}$ & 10.32 & 7.83 & $.000^{*}$ \\
\hline 5.Cognitivos & $8.48^{a}$ & $8.86^{a}$ & $8.99 a$ & $8.85^{a}$ & 8.80 & 11.60 & $.000^{*}$ \\
\hline
\end{tabular}

Nota. 1. Bem-estar profissional; 2. Distúrbios musculosqueléticos; 3. Alterações da voz; 4. Esgotamento; 5. Distúrbios cognitivos. ${ }^{*} p<.05$. a,b Médias na mesma linha com a letra igual representam grupos com diferenças estatisticamente significativas (teste post-hoc Bonferroni; $p=.05$ ). $N=5009$.

Em relação ao tempo de serviço (Tabela 8), a comparação de médias mostra-nos diferenças estatisticamente significativas em todas as dimensões. A maior diferença encontra-se na dimensão "distúrbios cognitivos" ( $F=20.30, p=.000)$. Os professores com 21 ou mais anos de serviço são aqueles que apresentam piores médias em todas as dimensões, observando-se diferenças maiores entre estes e os professores com menos tempo de serviço (0-5 anos).

Podemos verificar, através da análise com o teste post-hoc Bonferroni, que as diferenças estatisticamente significativas para a dimensão "bem-estar profissional" ocorrem entre os grupos que têm menos e mais anos de tempo de serviço ( ${ }^{a}$ - I.C. a 95\% ]-3.2644;-.2232 [; p=.015; b - I.C. a 95\% ]2.1178;-.1298[; $p=.017$ ). Na dimensão "alterações da voz" regista-se uma diferença significativa entre os grupos dos zero aos 5 anos de serviço e os de mais de 21 anos de serviço (I.C. a 95\% ]-.7611;-.1555[; $p=.000)$. Nas restantes dimensões verificamos que o grupo de professores com 21 ou mais anos de serviço regista diferenças significativas com todos aqueles que apresentam menos tempo de serviço (a, b, c - I.C. a 95\%; valores de $p$ entre .000 e 013).

Tabela 8. Resultados da Comparação de Médias em Função da Tempo de Serviço (anos)

\begin{tabular}{|c|c|c|c|c|c|c|c|}
\hline Dimensão & $\begin{array}{c}0-5 \\
n=138\end{array}$ & $\begin{array}{c}6-10 \\
n=332\end{array}$ & $\begin{array}{c}11-20 \\
n=1461\end{array}$ & $\begin{array}{c}\geq 21 \\
n=3078\end{array}$ & $\begin{array}{c}\text { Total } \\
n=5009\end{array}$ & $\mathbf{F}$ & $p$ \\
\hline 1.Bem-estar & $20.73^{\mathrm{a}}$ & $21.35^{b}$ & 22.13 & $22.48^{\mathrm{a}, \mathrm{b}}$ & 22.25 & 5.90 & $.001^{*}$ \\
\hline 2.Musculosq. & $9.97 \mathrm{a}$ & $10.31^{b}$ & $10.83^{c}$ & $11.08^{a, b, c}$ & 11.08 & 14.85 & $.000^{*}$ \\
\hline 3.Voz & 5.40 & $5.30^{\mathrm{b}}$ & 5.61 & $5.76^{b}$ & 5.68 & 7.11 & $.000^{*}$ \\
\hline 4.Esgotamento & $9.37^{a}$ & $9.70^{\mathrm{b}}$ & $10.22^{\mathrm{a}, \mathrm{b}, \mathrm{c}}$ & $10.48^{a, b, c}$ & 10.32 & 15.76 & $.000^{*}$ \\
\hline 5.Cognitivos & $7.92^{\mathrm{a}}$ & $8.29 b$ & $8.63^{a, c}$ & $8.97 \mathrm{a}, \mathrm{b}, \mathrm{c}$ & 8.80 & 20.30 & $.000^{*}$ \\
\hline
\end{tabular}

Nota. 1. Bem-estar profissional; 2. Distúrbios musculosqueléticos; 3. Alterações da voz; 4. Esgotamento; 5. Distúrbios cognitivos. ${ }^{*} p<.05$. a,b Médias na mesma linha com a letra igual representam grupos com diferenças estatisticamente significativas (teste post-hoc Bonferroni; $p=.05$ ). $N=5009$. 
Para o nível de ensino (Tabela 9) observam-se diferenças significativas em todas as dimensões. A maior diferença regista-se na dimensão "bem-estar profissional" $(F=23.44, p=.000)$. Os piores valores registam-se para os professores do 2. ciclo do ensino básico na dimensão "bem-estar profissional", para os do ensino pré-escolar na dos "distúrbios musculosqueléticos" e para os do 1.ำ ciclo do ensino básico nas dimensões "alterações de voz", "esgotamento" e "distúrbios cognitivos". Os professores do ensino profissional/artístico são os que menos sofrem de problemas relacionados com as dimensões de perda de saúde.

0 teste post-hoc Bonferroni revela diferenças estatisticamente significativas na dimensão "bemestar profissional" entre os professores do pré-escolar e os restantes grupos, à exceção dos professores do ensino profissional/artístico ( ${ }^{a}$ - I.C. a 95\%; $p=.000$ ). Registam-se, ainda, diferenças entre este último

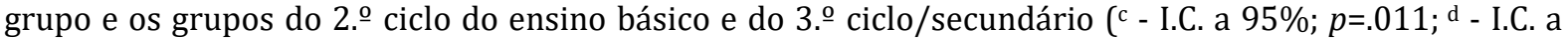
95\%; $p=.018)$.

0 grupo de professores do ensino profissional/artístico apresenta diferenças estatisticamente significativas com todos os outros grupos no que se refere às restantes dimensões (I.C. a 95\%; valores de $p$ entre .000 e .050), exceto nos "distúrbios cognitivos" onde esta diferença apenas não se verifica com o grupo do 3. ciclo/secundário (I.C. a 95\%; $p=.121$ ).Também os professores do ensino especial revelam diferenças significativas com todos os outros grupos, no que se refere à dimensão "alterações da voz" (I.C. a 95\%; valores de $p$ entre .000 e .033).

Tabela 9. Resultados da Comparação de Médias em Função do Nível de Ensino

\begin{tabular}{|c|c|c|c|c|c|c|c|c|c|}
\hline Dimensão & $\begin{array}{c}\text { Pré } \\
n=305\end{array}$ & $\begin{array}{c}19 \mathrm{O} C \\
n=754\end{array}$ & $\begin{array}{c}22^{\circ} \mathrm{C} \\
n=823\end{array}$ & $\begin{array}{c}3^{\circ} \mathrm{C} / \mathrm{Sec} \\
n=2824\end{array}$ & $\begin{array}{c}\text { Esp } \\
n=247\end{array}$ & $\begin{array}{c}\text { Prof/Art } \\
n=56\end{array}$ & $\begin{array}{c}\text { Total } \\
n=5009\end{array}$ & $\mathbf{F}$ & $p$ \\
\hline 1.Bem-estar & $18.61 \mathrm{a}$ & $22.31^{\mathrm{a}}$ & $22.76^{a, c}$ & $22.57 \mathrm{a}, \mathrm{d}$ & $21.92^{\mathrm{a}}$ & $20.07 c, d$ & 22.25 & 23.44 & $.000^{*}$ \\
\hline 2.Musculosq. & $11.83 a$ & $11.80^{\mathrm{b}}$ & $11.16^{\mathrm{b}, \mathrm{c}}$ & $10.78^{\mathrm{a}, \mathrm{b}, \mathrm{d}}$ & $11.77 \mathrm{~d}, \mathrm{e}$ & $9.21 \mathrm{a}, \mathrm{b}, \mathrm{c}, \mathrm{d}, \mathrm{e}$ & 11.08 & 16.62 & $.000^{*}$ \\
\hline 3.Voz & $5.76 a$ & $6.20 \mathrm{a}^{\mathrm{b}}$ & $5.73^{b, c}$ & $5.59 \mathrm{~b}, \mathrm{~d}$ & $5.14 \mathrm{a}, \mathrm{b}, \mathrm{c}, \mathrm{d}, \mathrm{e}$ & $4.32^{\mathrm{a}, \mathrm{b}, \mathrm{c}, \mathrm{d}, \mathrm{e}}$ & 5.68 & 22.00 & $.000^{*}$ \\
\hline 4.Esgotamento & $10.21 \mathrm{a}$ & $10.89^{a, b}$ & $10.48^{\mathrm{b}, \mathrm{c}}$ & $10.18^{\mathrm{b}, \mathrm{d}}$ & $10.30^{\mathrm{b}, \mathrm{e}}$ & $8.81^{\mathrm{a}, \mathrm{b}, \mathrm{c}, \mathrm{d}, \mathrm{e}}$ & 10.32 & 13.77 & $.000^{*}$ \\
\hline 5.Cognitivos & $8.96 a$ & $9.20^{\mathrm{b}}$ & $8.78^{b, c}$ & $8.6^{b}$ & $9.06^{\mathrm{e}}$ & $7.94 \mathrm{a}, \mathrm{b}, \mathrm{c}, \mathrm{e}$ & 8.80 & 9.07 & $.000^{*}$ \\
\hline
\end{tabular}

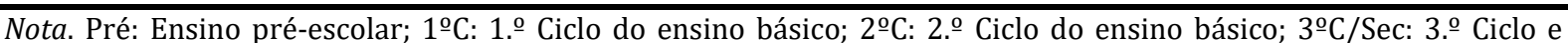
ensino secundário; Esp: Ensino especial; Prof/Art: Ensino artístico e profissional.

1. Bem-estar profissional; 2. Distúrbios musculosqueléticos; 3. Alterações da voz; 4. Esgotamento; 5. Distúrbios cognitivos. ${ }^{*} p<.05$. a,b,c,d,e Médias na mesma linha com a letra igual representam grupos com diferenças estatisticamente significativas. (teste post-hoc Bonferroni; $p=.05$ ). $N=5009$.

A análise de clusters ofereceu uma solução a três grupos. Cada deles foi caracterizado em função das variáveis género, idade, tipo de ensino, tempo de serviço e nível de ensino (Tabela 10).

0 primeiro grupo $(N=1601 ; 32 \%)$ com as pontuações mais elevadas (entre 105 e 75) foi categorizado como saúde alta. Neste grupo encontramos, maioritariamente, professores do género masculino (44.2\%), com idades compreendidas entre os 21 e 42 anos (35.6\%), do ensino privado (45.6\%), entre os 0 e os 5 anos de serviço (44.0\%) e a lecionar no ensino profissional/artístico (52.8\%).

O segundo grupo $(N=2283 ; 45.6 \%)$ com pontuações médias (entre 74 e 58 ) foi categorizado como saúde média. Quase metade (46 a 49.1\%) dos professores que compõe este grupo é do género feminino, entre os 43 e 49 anos, a lecionar no 1. ciclo do ensino básico (público), com 11 a 20 anos de serviço.

O terceiro grupo $(N=1125 ; 22.4 \%)$ com pontuações baixas (entre 57 e 21) foi categorizado como saúde baixa. Este grupo é caracterizado por $24.8 \%$ de professores do género feminino, entre os 50 e os 55 anos (25.7\%), do ensino público (23.2\%), com 21 ou mais anos de serviço (25.5\%) e a lecionar no 1. o ciclo do ensino básico (26.3\%). 
Tabela 10. Distribuição dos níveis de saúde docente em função das variáveis sociodemográficas e profissionais

\begin{tabular}{|c|c|c|c|c|c|}
\hline & & IS Alta (\%) & IS Média (\%) & IS Baixa (\%) & $p$ \\
\hline \multirow[t]{2}{*}{ Género } & Feminino & 28.4 & 46.8 & 24.8 & \multirow{2}{*}{$.000^{*}$} \\
\hline & Masculino & 44.2 & 41.4 & 14.4 & \\
\hline \multirow[t]{4}{*}{ Idade } & 21 a 42 anos & 35.6 & 47.0 & 17.4 & \multirow{4}{*}{$.001^{*}$} \\
\hline & 43 a 49 anos & 29.8 & 48.1 & 22.2 & \\
\hline & 50 a 55 anos & 30.2 & 44.1 & 25.7 & \\
\hline & 56 a 70 anos & 32.7 & 42.5 & 24.8 & \\
\hline \multirow[t]{2}{*}{ Tipo de instituição } & Pública & 30.8 & 46.0 & 23.2 & \multirow{2}{*}{$.000^{*}$} \\
\hline & Privada & 45.6 & 40.4 & 14.0 & \\
\hline \multirow[t]{4}{*}{ Tempo de serviço } & $0-5$ anos & 44.0 & 47.8 & 8.2 & \multirow{4}{*}{$.000^{*}$} \\
\hline & $6-10$ anos & 40.5 & 45.4 & 14.1 & \\
\hline & $11-20$ anos & 32.0 & 48.6 & 19.4 & \\
\hline & $\geq 21$ anos & 30.5 & 44.0 & 25.5 & \\
\hline \multirow[t]{6}{*}{ Nível de ensino } & Pré-escolar & 41.6 & 40.3 & 18.0 & \multirow{6}{*}{$.000^{*}$} \\
\hline & 1. ${ }^{\circ}$ Ciclo & 24.6 & 49.1 & 26.3 & \\
\hline & 2. ${ }^{\circ}$ Ciclo & 30.5 & 45.9 & 23.6 & \\
\hline & 3. Ciclo/Secundário & 32.9 & 45.1 & 21.9 & \\
\hline & Ed. Especial & 30.1 & 46.5 & 23.5 & \\
\hline & Profissional/Artístico & 52.8 & 40.3 & 6.9 & \\
\hline
\end{tabular}

Nota. IS - Índice de Saúde. ${ }^{*} p \leq .05$

\section{DISCUSSÃO}

A qualidade do ensino e o consequente sucesso dos alunos e da organização escolar depende do estado de saúde dos professores, o que justifica a importância de avaliar periodicamente o estado de saúde destes profissionais. Com este propósito, foi realizada a adaptação e validação do QSD para os docentes portugueses do ensino básico e secundário. Após a AFC, com reespecificação das estruturas fatoriais consideradas, optámos pelo modelo com 5 fatores correlacionados (M2) tendo em consideração os índices de ajustamento, os fundamentos teóricos e empíricos, e o facto de ser aquele que melhor se adequa ao fenómeno em estudo. Os resultados obtidos permitem suportar uma estrutura penta fatorial com índices de ajustamento que sustentam a boa qualidade deste modelo para avaliar a saúde dos professores e ainda com valores que reforçam a sua fiabilidade e validade.

Este questionário contribui de forma positiva para a investigação nesta área, pois apresenta características que o tornam um instrumento importante na avaliação da saúde e dos principais riscos associados à profissão docente e na promoção da saúde na docência, tais como: (a) a inclusão num só instrumento dos principais riscos, doenças ou patologias associadas à profissão e das manifestações de bem-estar e funcionamento ótimo do professor; (b) a sua utilidade como instrumento para a avaliação individual e coletiva da organização escolar; (c) a dedicação exclusiva à valorização do estado de saúde do docente, distinguindo-se de outros questionários que avaliam fatores de risco; (d) a qualidade das suas propriedades psicométricas; (e) a brevidade do mesmo, que permite uma cómoda aplicação e sua combinação com outros instrumentos para efeitos de investigação; (f) os custos reduzidos na sua administração, pontuação e interpretação; (g) a utilidade para a realização de avaliações periódicas de saúde ocupacional, de acordo com os objetivos estratégicos da European Commission's Strategy Framework for Safety and Health at Work from 2014-2020 (2014).

\section{Perceção dos docentes portugueses relativamente à sua saúde}

A versão portuguesa do QSD é constituída por cinco fatores: bem-estar profissional, esgotamento, distúrbios cognitivos, distúrbios musculosqueléticos e alterações da voz.

Podemos constatar que, mais de metade dos participantes sente mal-estar no exercício da sua profissão o que vai ao encontro dos resultados de estudos anteriores (e.g., Esteve, 1994; Jesus, 2004; Jesus \& Resende, 2009; Ramos, 2012). Estes percecionam níveis de autoeficácia e satisfação profissional muito inferiores aos manifestados pelos professores espanhóis e brasileiros (Fernández-Puig et al., 2015b; Zacharias, 2011). Significa que os docentes se sentem insatisfeitos, desmotivados, e possuem uma fraca perceção das suas competências e capacidades para desempenhar a sua atividade profissional, com 
consequências negativas no seu bem-estar profissional, já que segundo Jesus $(2007,2011)$ um professor que apresenta um nível ótimo de bem-estar manifesta uma elevada satisfação profissional e elevadas expectativas de eficácia.

Os professores com menor bem-estar profissional e que sofrem mais de doenças relacionadas às dimensões de perda de saúde, são os do ensino público, do género feminino, a lecionar no 2.ํㅜ ciclo, que se encontram numa faixa etária mais elevada e, naturalmente, com mais o tempo de serviço, resultados estes que corroboram com os obtidos em outros estudos (Borba et al., 2015; Ferreira-Esteves et al., 2014; Fernández-Puig et al., 2015b; ; FNE, 2015; Kokkinos, 2007; Santos, 201; Scheuch et al., 2015; Yue et al.,2012;).

Podemos constatar que existe uma tendência para o bem-estar diminuir à medida que o ciclo de ensino aumenta, situação esta que é semelhante à dos professores espanhóis, visto que os ensino secundário apresentam menor satisfação e autoeficácia (Fernández-Puig et al., 2015b).

O esgotamento é o principal problema de saúde percecionado pelos professores do género feminino, do setor público e a lecionar no $1 .{ }^{\circ}$ ciclo do ensino básico, corroborando os resultados obtidos em outros estudos (e.g., Carlotto, 2011; Fernández-Puig et al., 2015b; Gomes et al., 2010; Jesus, 2007; Martins, 2008; Patrão et al., 2012; Ramos, 2012). No entanto, Dubey e Kumar (2017) encontraram maior nível de stresse nos professores do ensino secundário, embora com diferenças pouco significativas relativamente ao burnout. Este cenário pressupõe uma situação de risco, visto que a vivência de esgotamento aumenta a vulnerabilidade do indivíduo desenvolver problemas de índole física e psicológica (Gil-Monte, 2005). Sendo este fator considerado uma dimensão central do burnout, é decisivo nas espirais negativas ou de perda de saúde, indicando uma sobrecarga de trabalho. Sendo evidente que as diferenças entre géneros, setor e nível de ensino onde lecionam afetam o estado de saúde dos docentes, é importante perceber quais as características pessoais, contextuais e organizacionais que diferenciam estes grupos.

A diminuição do bem-estar e o incremento de esgotamento à medida que a idade e o tempo de serviço aumentam, indicam-nos um elevado risco de burnout em função destas variáveis (Fernández-Puig et al., 2015b), evidenciando a necessidade de antecipar a idade e/ou do tempo de serviço para a aposentação nesta classe profissional.

Valente et al. (2015) verificaram que o stresse e o burnout no trabalho foram fatores associados, também, aos problemas da voz em professores, o que significa que estes riscos psicossociais podem ter repercussões ao nível das várias dimensões de perda de saúde.

Os resultados na dimensão distúrbios cognitivos são semelhantes aos obtidos por Goulart Júnior e Lipp (2008). Os problemas de concentração são menores nos professores portugueses quando comparados com os resultados de outros estudos (Fernández-Puig et al., 2015b; ADEMYS, 2011). No entanto, sofrem mais de problemas de memória que os espanhóis. Os professores do 1.ํ ciclo do ensino básico são os que apresentam mais problemas relacionados com esta dimensão.

Os resultados demonstram uma considerável prevalência de distúrbios músculo-esqueléticos, tal como acontece em outros estudos (e.g., Férnandez-Puig et al., 2015b; Rottermund et al., 2015; Yue \& Li, 2012; Zamri et al., 2017), mais acentuados nas mulheres e nos professores do ensino pré-escolar, o que é coincidente com os resultados obtidos por Fernández-Puig et al. (2015b). Este facto pode ser explicado pela tenra idade dos alunos que dependem da ajuda do professor para realizar muitas das suas tarefas, e porque os docentes passam grande parte do tempo numa posição que lhes permite o contacto direto com estes alunos. Constatamos que estes problemas diminuem à medida que o nível de ensino aumenta, o que parece reforçar a validade desta fundamentação.

As alterações da voz são similares às verificadas nos estudos de Guimarães (2004) e da FNE (2015). A sua incidência é menor que a dos professores indianos e brasileiros (Alva et al., 2017; Valente et al., 2015), e maior do que a dos espanhóis (Fernández-Puig et al., 2015b). Os professores do 1. ํㅜclo e pré-escolar apresentaram mais problemas na voz, resultados estes idênticos aos obtidos pela ADEMYS (2011). Os estudos de Alva et al. (2017) não verificaram diferenças significativas nas alterações da voz em função do tempo de serviço dos professores, resultados estes distintos dos obtidos neste estudo.

Em relação às dimensões relacionadas com a perda de saúde, verificamos que os professores do 1.ํㅜㅇ ciclo do ensino básico são os que mais sofrem de problemas relacionados com o esgotamento, distúrbios cognitivos e alterações da voz, o que pode ser justificado pelas características do ensino em monodocência e à faixa etária dos alunos.

Os distúrbios cognitivos, musculosqueléticos e as alterações na voz, registam piores resultados para os professores entre os 50 e 55 anos, melhorando ligeiramente entre os 56 e os 70 anos. Este facto assinala a importância de prevenir a diminuição das capacidades associadas a estas dimensões de saúde, situação que parece estar mais associada ao stresse e esgotamento do docente (Goulart Júnior \& Lipp, 2008; Suda et al., 2011; Valente et al., 2015) do que ao acréscimo da idade, pois se assim fosse, estas 
capacidades continuariam a diminuir nos professores com mais de 55 anos, o que não se verifica. Os resultados nestas três dimensões são idênticos aos manifestados pelos professores espanhóis (Fernández-Puig et al., 2015b).

A análise de clusters com base no índice de saúde, permitiu-nos definir três níveis de intervenção diferenciados, caracterizados em função das variáveis: género, tipo de instituição, nível de ensino, idade e tempo de serviço. Um primeiro nível onde $22.4 \%$ dos professores apresentam baixos resultados e cuja intervenção a realizar deve ser, essencialmente, ao nível do tratamento dos problemas diagnosticados e de promoção do bem-estar profissional; um segundo nível (saúde média), com 45.6\%, onde devemos incidir com intervenção preventiva; e um terceiro nível (saúde alta), com 32\%, que evidenciam um grupo de professores resilientes, envolvidos na sua profissão e que experienciam bem-estar e que, como tal, deverão ser melhor investigados no sentido de nos ajudarem a identificar modelos promotores de saúde e bem-estar na profissão docente.

Encontram-se mais professores portugueses no índice de saúde mais baixo e menos nos índices médio e alto, quando comparados com os professores espanhóis (Fernández-Puig et al., 2015b).

Com base no conjunto de respostas obtidas em cada uma das suas dimensões (bem-estar profissional, distúrbios musculosqueléticos, esgotamento, alterações da voz e distúrbios cognitivos), podemos afirmar que mais de metade dos professores que participaram neste estudo apresentam um fraco bem-estar profissional e sofrem de problemas nas várias dimensões de perda de saúde.

0 estudo revela que as dimensões relacionadas com a saúde mental (bem-estar profissional, esgotamento e os distúrbios cognitivos) são as que mais contribuem para a deterioração da saúde docente, seguindo-se as alterações da voz e os distúrbios musculosqueléticos, apresentando cada uma destas, ainda assim, um risco para a saúde em mais de metade dos professores.

Os resultados permitiram-nos diagnosticar três grupos de professores com diferentes níveis de saúde (baixo, médio, alto), caracterizados em função de algumas variáveis sociodemográficas e profissionais, que nos dão informações importantes para a construção e aplicação de programas de intervenção diferenciados nas escolas portuguesas.

Os professores do género feminino, das escolas públicas, a lecionar no 1. ciclo do ensino básico, entre os 56 e os 70 anos de idade e com 21 ou mais anos de serviço são os que apresentam menor bemestar profissional e mais problemas de saúde, tendo sido avaliados com um baixo índice de saúde. No índice de saúde mais elevado e, portanto, com maior bem-estar e menos problemas de saúde, encontramos os professores do género masculino, de escolas privadas, que lecionam no ensino profissional/artístico, dos 21 aos 42 anos de idade e com menos tempo de serviço.

A análise dos resultados obtidos, reforça a necessidade de ser adotadas políticas educativas que promovam, efetivamente, a saúde e o bem-estar profissional dos docentes portugueses. Como por exemplo, programas de treino vocal para preparar os professores para um uso profissional e saudável da voz, a aplicação de programas de prevenção e de gestão do stresse e da promoção do bem-estar, que deverão ser diferenciados ao longo da carreira docente e de outras variáveis cujos as análises entre grupos revelaram diferenças significativas.

\section{Limitações e Sugestões Futuras}

Este estudo possui algumas limitações. Uma delas prende-se com o facto de termos utlizado um design transversal, pois sendo conscientes de que a saúde é mais um processo do que um estado, era importante dispormos de estudos nesta área mais consistentes, com recurso a designs longitudinais, que permitissem observar as mudanças ao longo do tempo e o seu impacto na saúde dos professores e na organização escolar.

Apesar da amostra ser considerável, consideramos uma outra limitação o facto de as comparações entre grupos terem sido realizadas com um número muito díspar de participantes por grupo, apesar de não se terem verificado violações dos pressupostos na realização das análises estatísticas. Esta situação deve ser corrigida em estudos futuros.

Destacamos, também, a falta de inclusão de instrumentos que permitam valorizar a validade (convergente e divergente) do instrumento, pese embora a dificuldade em encontrar questionários que reúnam um conjunto similar de manifestações relacionadas com a saúde na profissão docente. No entanto, e por forma a melhorar as propriedades psicométricas do QSD, sugere-se que os estudos futuros que utilizem esta escala apliquem instrumentos que meçam constructos, tais como o burnout, o stresse, o bem-estar, a saúde geral, entre outros. Isto seria viável dada a brevidade do QSD.

Sugere-se que futuras linhas de investigação explorem a relação entre as várias dimensões de saúde docente e os constructos da psicologia organizacional positiva. Outra possível linha de investigação (longitudinal) interessante poderá incidir na monotorização/avaliação de programas de saúde, especialmente a saúde mental e bem-estar organizacional. Estes programas devem comtemplar não só o 
diagnóstico nas várias dimensões de saúde do coletivo de professores de uma escola/agrupamento, mas também a construção e aplicação de programas de intervenção diferenciados no contexto da organização escolar, com a colaboração de entidades e profissionais especializados.

Por fim, propomos que se estude a relação entre as várias dimensões de saúde docente e os resultados dos alunos e/ou processo ensino e aprendizagem.

\section{QUESTIONÁRIO DE SAÚDE DOCENTE (QSD)}

Com o intuito de facilitar o acesso, tanto a investigadores da área da saúde como da educação, apresentamos a versão portuguesa do QSD que resultou do presente estudo.

\section{Instruções}

“No questionário abaixo encontrará algumas afirmações sobre o seu trabalho e a sua saúde. Valorize em que medida cada uma delas expressa o que vivenciou nos últimos meses. Por favor, assinale com uma X a resposta que melhor reflete a sua perceção. Tenha presente que não há respostas corretas ou incorretas e que o mais importante é a sua sinceridade."

Escala

1 = Nunca; 2 = Raramente; 3 = Algumas vezes; 4 = Frequentemente; 5 = Quase sempre

Itens

1. Tenho dor na zona da nuca

2. Tenho a impressão que fico obcecado(a) com um assunto que noutro momento poderia resolver sem problema

3. Sinto-me satisfeito(a) com a minha forma de fazer as coisas

4. As minhas costas ressentem-se devido à atividade que faço

5. Se pudesse, voltaria a escolher ser professor(a)

6. Depois de um dia de trabalho sinto-me sem forças

7. Noto que estou afónico(a) ou disfónico(a)

8. Em alguns momentos, tenho falta de concentração para realizar tarefas

9. Desfruto das minhas tarefas quotidianas

10. Sou muito feliz no meu trabalho

11. Sinto-me fisicamente cansado(a) no final do meu dia de trabalho

12. Quando termino um trabalho, fico contente com os resultados

13. Sinto dor no pescoço depois de um dia de trabalho.

14. Divirto-me no trabalho

15. A minha voz cansa-se facilmente.

16. No trabalho, fico muito cansado(a)

17. Quando acordo, tenho vontade de ir trabalhar

18. Estou satisfeito(a) com a minha participação na escola

19. Sofro de lombalgia

20. Tenho a capacidade de ser criativo(a) e ágil na minha atividade docente

21. Ultimamente tenho falta de memória

\section{REFERÊNCIAS}

Almeida, L., \& Freire, T. (2017). Metodologia da investigação em psicologia e educação (5a Ed.). Psiquilíbrios Edições.

Asociación Docente de Enseñanza Media y Superior (2011). Salud y condiciones de trabajo en el sector docente: Diagnóstico y respuestas posibles. ADEMYS

Alva, A., Machado, M., Bhojwani, K., \& Sreedharan, S. (2017). Study of risk factors for development of voice disorders and its impact on the quality of Life of school teachers in Mangalore, India. Journal of Clinical and Diagnostic Research, 11, 1-5. http://dx.doi.org/10.7860/JCDR/2017/17313,9234

Alvear, R. M., Martínez-Arquero, L., Barón, F. J., \& Hernández-Mendo, A. (2010). An interdisciplinary approach to teacher's voice disorders and psychosocial working conditions. Folia Phoniatrica et Logopaedica, 62, 24-34. http://dx.doi.org/10.1159/000239060

Borba, B., Diehl, L., Santos, A., Monteiro, J., \& Marin, A. (2015). Burnout syndrome in teachers: A comparative study between the public and private education. Psicologia Argumento, 33, 270-281. http://dx.doi.org/10.7213/psicol.argum.33.080.A004

Gomes, ... M. Taveira (Ed.), Actas do VII Simpósio Nacional de Investigação em Psicologia. 1066-1080. Braga, Portugal: FPCEUP.

Csikszentmihalyi, M. (1990). Flow: The psychology of optimal experience. Harper and Row. 
Dubey, S., \& Kumar, R. (2017). A comparative study of job stress and burnout among teachers on the basis of their job level. Kaav International Journal of Economics, Commerce \& Business Manegement, 4, 189-193.

Duran, M., Extremera, N., Montalban, F. M., \& Rey, L. (2005). Engagement and burnout in teaching environment: Analysis of their relationships with Job and life satisfaction in a sample of teachers. Revista de Psicologia del Trabajo y de las Organizaciones, 21, 145-158.

Dybowski, C., Sehner, S., \& Harendza, S. (2017). Influence of motivation, self-efficacy and situational factors on the teaching quality of clinical educators. BMC Medical Education. Advance online publication. http://dx.doi.org/10.1186/s12909-017-0923-2

Eysenbach, G. (2012). Correction: Improving the Quality of Web Surveys: the checklist for reporting results of internet E-surveys (CHERRIES). Journal of Medical Internet Research, 14, e8. http://dx.doi.org/10.2196/jmir.2042

Erick, P., \& Smith, D. (2011). A systematic review of musculoskeletal disorders among school teachers. BCM Muskoloskeletal Disorders, 12, 260-271. http://dx.doi.org/10.1186/1471-2474-12-260

European Trade Union Committee for Education (2011). Teacher's work-related stress: Assessing, comparing and evaluating the impact of psychosocial hazards on teachers at their workplace. ETUCE.

European Commission's Strategic Framework on Health and Safety at Work 2014-2020 (2013). Communication from the Comission to the European Parlament, the Concil, the European Economic and Social Commitee and the Committee of the Regions. European Commission. http://www.eurogip.fr/images/documents/3771/EU_strategic_framework.pdf

Federação Nacional da Educação (2015). Saúde e segurança entre os profissionais da educação. FNE

Fernández-Puig, V., Mayayo, J., Lusar, A., \& Tejedor, C. (2015a). Evaluando la salud laboral de los centros concertados: El cuestionario de salud docente. Journal of Work and Organizational Psychology, 31, 175-185. http://dx.doi.org/10.1016/j.rpto.2015.07.001

Fernández-Puig, V., Chamarro, A., \& Longás, J. (2015b). Evaluando la salud laboral docente: Estúdio psicométrico del cuestionario de salud docente. (Tesis doctoral no publicada). Unversidad Ramon Lull-Facultat de Psicologia, Ciències de l'Educació i de l'Esport Blanquerna, Barcelona: España.

Ferreira-Esteves, A., Santos, D., \& Rigolon, R. (2014). Avaliação comparativa dos sintomas da síndrome de burnout em professores de escolas públicas e privadas. Revista Brasileira de Educação, 19, 9871002.

Gil-Monte, P. (2005). El síndrome de quemarse por el trabajo (burnout). Una enfermedad laboral en la sociedad del bienestar. Pirámide.

Gjersing, L., Caplehorn, J., \& Clauten, T. (2010). Cross-cultural adaptation of research instruments: language, setting, time and statistical considerations. BMC Medical Research Methodology, 10, 1013. https://dx.doi.org/10.1186/1471-2288-10-13

Gomes, R., Montenegro N., \& Peixoto, A. (2010). Stress ocupacional no ensino: um estudo com professores dos 3o ciclo e ensino secundário. Psicologia \& Sociedade, 22, 587-597.

Guimarães, I. (2004). Os problemas de voz nos professores: Prevalência, causas, efeitos e formas de prevenção. Revista Portuguesa de Saúde Pública, 22(2), 31-39.

Hair, J. F., Black, W. C., Babin, B. J., Anderson, R. E., \& Tatham, R. L. (2009). Análise multivariada dos dados (6 $6^{\mathrm{a}}$ ed.). Bookman.

Jaffe, D. (1995). The healthy company: Research paradigms for personal and organizational health. In S. Sauter \& L. Murphy (Coords.), Organizational risk factors for job stress (pp. 13-39). American Psychological Association.

Jesus, S. (2004). Psicologia da educação. Quarteto

Jesus, S. (2007). Professor sem stress: Realização profissional e bem-estar docente. Mediação.

Jesus, S., \& Conboy, J. (2001). A stress management course to prevent teacher distress. International. Journal of Educational Management, 15,131-137. https://dx.doi.org/10.1108/09513540110384484

Jesus, S., \& Rezende, M. (2009). Saúde e bem-estar. In J. Cruz, S. Jesus \& C. Nunes (Eds.). Bem-estar e qualidade de vida: Contributos da psicologia da saúde. Textiverso.

Jesus, S., Mosquera, J., Stobaus, C., Sampaio, A., Resende, M., \& Mascarenhas, S. (2011). Avaliação da motivação e do bem/mal estar dos professores. Estudo comparativo entre Portugal e Brasil. AMAzônica, 7(2), 7-18.

Junior, G., \& Lipp, M. (2008). Estresse entre professoras do ensino fundamental de escolas públicas estaduais. Psicologia em Estudo, 13, 847-857.

Kline, R. (2011). Principles and practice of structural equation modeling. Guilford Press. 
Klusmann, U., Richter, D., \& Lüdtke, O. (2016). Teachers' emotional exhaustion is negatively related to students' achievement: Evidence from a large-scale assessment study. Journal of Educational Psychology, 108, 1193-1203. http://dx.doi.org/10.1037/edu0000125

Kokkinos, C. M. (2007). Job stressors, personality and burnout in primary school teachers. British Journal of Educational Psychology, 77(1), 229-243. http://dx.doi.org/10.1348/000709905X90344

Lisboa, S. (2012). Satisfação dos colaboradores e a gestão da qualidade. Impacto da certificação ISSO 9001 na satisfação global dos colaboradores da câmara municipal da Maia (Dissertação de mestrado não publicada). Universidade Fernando Pessoa: Porto

López-Araujo, A., Segovia, S., \& Peiró, J. M. (2007). El papel modulador de la implicación con el trabajo en la relación entre el estrés y la satisfacción laboral. Psicothema, 19, 81-87.

Mack, J., Jonhson, A., Ricon, A., Tsatenawa, V., \& Howard, K. (2019). Why do teachers leave? A comprehensive occupational health study evaluating intent-to-quit in public school teachers. Journal of Applied Biobehavioral Research, 24:e12160. https://dx.doi.org/10.1111/jabr.12160

Maslach, C., Schaufeli, W. B., \& Leiter, M. (2001). Job burnout. Review of Psychology, 52, 397-422.

Marôco, J. (2018). Análise estatística com o SPSS statistics. (7a Ed.). ReportNumber.

Marôco, J. (2014). Análise de equações estruturais: fundamentos teóricos, software e aplicações (2ª Ed.). ReportNumber.

Mesaria, S., \& Jaiswal, N. (2015). Musculoskeletal disorders among teachers residing in various nations: A review. Research Journal of Recent Sciences, 4, 23-27.

Montero, I., \& León, O. (2007). A guide for naming research studies in psychology. International Journal of Clinical and Heath Psychology, 7, 847-862.

Moura, D. (2013). Engagement no trabalho: A perspetiva do modelo demandas-recursos laborais (Tese de mestrado não publicada). Faro, Portugal, Universidade do Algarve.

Nusseck, M., Spahn, C., Echternach, M., Immerz, A., \& Richter, B., 2018). Vocal Health, Voice Self-concept and Quality of Life in German School Teachers. Journal of Voice. In Press, Corrected Proof https://dx.doi.org/10.1016/j.jvoice.2018.11.008

Patrão, I., Rita, J., \& Marôco, J. (2012). Avaliação do burnout em professores: Contributo para o estudo de adaptação do CBP-R. Psychology, Community \& Health, 1(2), 179-188.

Ramos, A. (2012). Stresse percebido, burnout, estratégias de coping e estilos de vida em docentes portugueses (Tese de doutoramento não publicada). UTL-FMH, Lisboa, Portugal.

Rottermund, J., Knapik, A., Saulicz, E., Myśliwiec, A., Saulicz, M., Anna Rygiel, K., \& Linek, P. (2015). Back and neck pain among school teachers in Poland and its correlations with physical activity. Medycyna Pracy, 66, 771-778. http://dx.doi.org/10.13075/mp.5893.00121

Rudow, B. (1999). Stress and burnout in the teaching profession: European studies, issues and perspectives. In A. M. Huberman (Ed.), Understanding and preventing teacher burnout. A sourcebook of international research and practice (pp. 38-58). Cambridge University Press. http://dx.doi.org/10.1017/ CB09780511527784.004

Rumschlag, K. (2017). Teacher burnout: A quantitative analysis of emotional exhaustion, personal, accomplishment, and depersonalization. International Management Review, 13, 22-36.

Salanova, M., Llorens, S., \& Schaufeli, W.B. (2011). “Yes, i can, i feel good, and i just do it!” On gain cycles and spirals of efficacy beliefs, affect, and engagement. Applied Psychology. An International Review, 60, 255-285. http://dx.doi.org/10.1111/j.1464-0597.2010.00435.x

Salanova, M., Martínez, I., \& Llorens, S. (2014). Una mirada más "positiva” de la salud ocupacional desde la psicologia organizacional positiva en tempos de crisis: Aportaciones desde el equipo de investigación WoNT. Papeles del Psicólogo, 35(1), 22-30.

Santos, S. (2011). Burnout e diferenças de género em professores (Dissertação de mestrado não publicada). Universidade Lusófona de Humanidades e Tecnologias, Lisboa, Portugal.

Sarath, P., \& Manikandan, K. (2014). Work engagement and work related wellbeing of school teachers. SELP Journal of Social Science, V(22), 93-100.

Schaufeli, W. B., Salanova, M., González-Romá, V., \& Bakker, A. B. (2002). The measurement of engagement and burnout: A two sample confirmatory analytic approach. Journal of Happiness, 3, 71-92.

Scheuch K., Haufe E., \& Seibt R. (2015). Teachers' health. Deutsches Ärzteblatt International, 112, 347-56. http://dx.doi.org/10.3238/arztebl.2015.0347

Sousa, M. (2016). Satisfação profissional e bem-estar docente: Um estudo com professores do ensino superior público do Lubango (Angola) (Dissertação de mestrado não publicada). Faculdade de Psicologia e Ciências da Educação da Universidade de Coimbra, Coimbra, Portugal.

Suda, E., Coelho, A., Bertaci, A., \& Santos, B. (2011). Relationship between general level of health, musculoeskeletal pain and occurrence of burnout syndrome in college teachers. Fisioterapia $e$ Pesquisa, 18, 270-274. http://dx.doi.org/10.1590/S1809-29502011000300012 
Valente, A., Botelho, C., \& Silva, A. (2015). Voice disorder and associated factors among public schools teachers. Revista Brasileira de Saúde Ocupacional, 40(132), 183-195. http://dx.doi.org/10.1590/0303-7657000093814

Viseu, J. (2017). A motivação profissional dos docentes do ensino básico e secundário: A influência de variáveis organizacionais, individuais e pertencentes à interface sujeito-organização (Dissertação de doutoramento não publicada). Universidade do Algarve: Faro.

World Health Organization, Constitution of WHO: Principles (1947). Constitution of the World Health Organization. WHO.

Yang, R., You, X., Zhang, Y., Lian, L., \& Feng, W. (2019). Teachers' mental health becoming worse: The case of China. International Journal of Educational Development, 70 (102077). https://dx.doi.org/10.1016/j.ijedudev.2019.102077

Yue, P., Fengying Liu, F., \& Li, L. (2012). Neck/shoulder pain and low back pain among school teachers in China, prevalence and risk factos. BMC Public Health, 12, 789.

Zacharias, J., Mendes, A., Lettnin, C., Dohms, K., Mosquera, J., \& Stobäus, C. (2011). Saúde e educação: Do mal-estar ao bem-estar docente. Revista Educação por Escrito - PUCRS, 2(1), 16-30.

Zamri, E., Moy, F., \& Hoe, V. (2017). Association of psychological distress and work psychosocial factors with self-reported musculoskeletal pain among secondary school teachers in Malaysia. PLoS ONE 12(2), 1-15. https://dx.doi.org/10.1371/journal.pone.0172195

Historial do artigo

Recebido 03/2019

Aceite $\quad 04 / 2020$

Publicado 08/2020 